\title{
Impactos maternos da Sífilis durante a gestação: uma revisão bibliográfica
}

\author{
Maternal impacts of Syphilis during pregnancy: a bibliographic review \\ Impactos maternos de la Sífilis durante el embarazo: una revisión bibliográfica
}

Aline Teixeira de Sousa ${ }^{1 *}$, Bruna Furtado Sena de Queiroz ${ }^{1}$, Letícia Costa Rodrigues ${ }^{1}$, Isabele Karine Machado da Silva ${ }^{1}$, Stephanie Mendes da Silva ${ }^{1}$, Willana de Queiroz Nepomuceno², Márcia de Sousa Silva ${ }^{1}$, Franciele Ferreira de Sousa ${ }^{1}$, Jade Maria Bezerra Cortez ${ }^{1}$, Kamila Cristiane de Oliveira Silva ${ }^{1}$.

\section{RESUMO}

Objetivo: Identificar as evidências científicas acerca dos impactos da sífilis durante a gestação. Revisão bibliográfica: A sífilis é uma infecção sexualmente transmissível (IST), causada pela bactéria treponema pallidum, forma de transmissão principal via sexual (sífilis adquirida) e vertical (sífilis congênita), sendo que a vertical é a infecção onde a bactéria é transmitida da mãe para o concepto, ocasionando SG, infecção de alta prevalência mundial, sendo encontrada em quatro estágios: primário, secundário, latente e terciário. Foi possível observar os impactos que a sífilis causa durante a gestação, sua alta prevalência em mulheres jovens, com baixa escolaridade e classe social baixa; como prevenir está infecção e como tratar; forma de transmissão; riscos e agravos causados nas gestantes. Considerações finais: A necessidade da realização de pré-natal de qualidade, tratamento eficaz contra a sífilis durante a gestação evitando seus agravos, para consequentemente evitar aborto, parto prematuro, sífilis vertical e sífilis congênita. A sífilis tem impacto negativo na vida das pessoas. Constatou-se nesse estudo que a produção científica em relação ao tema é muito grande e que a realização de exames e acompanhamento das gestantes durante o pré-natal é indispensável.

Palavras-chave: Gravidez, Sífilis, Treponema pallidum.

\begin{abstract}
Objective: To identify the scientific evidence about the impacts of syphilis during pregnancy. Bibliographic review: Syphilis is a sexually transmitted infection (STI), caused by the bacterium treponema pallidum, the main form of sexual transmission (acquired syphilis) and vertical (congenital syphilis), the vertical being the infection where the bacterium is transmitted from mother to the fetus, causing SG, a highly prevalent infection worldwide, being found in four stages: primary, secondary, latent and tertiary. It was possible to observe the impacts that syphilis causes during pregnancy, its high prevalence in young women, with low education and low social class; how to prevent this infection and how to treat it; form of transmission; risks and injuries caused by pregnant women. Final considerations: The need for quality prenatal care, effective treatment against syphilis during pregnancy, avoiding its problems, in order to avoid abortion, premature birth, vertical syphilis and congenital syphilis. Syphilis has a negative impact on people's lives. It was found in this study that the scientific production in relation to the theme is very large and that the performance of exams and monitoring of pregnant women during prenatal care is essential.
\end{abstract}

Key words: Pregnancy, Syphilis, Treponema pallidum.

\footnotetext{
${ }^{1}$ Centro Universitário UNIFACID, Teresina - PI. `E-mail: alineteixeiras@hotmail.com

2 UNINOVAFAPI, Teresina - PI.
}

SUBMETIDO EM: 3/2021

ACEITO EM: 4/2021

PUBLICADO EM: 4/2021 


\section{RESUMEN}

Objetivo: Identificar la evidencia científica sobre los impactos de la sífilis durante el embarazo. Revisión bibliográfica: La sífilis es una infección de transmisión sexual (ITS), causada por la bacteria treponema pallidum, principal forma de transmisión sexual (sífilis adquirida) y vertical (sífilis congénita), siendo la vertical la infección donde la bacteria se transmite de madre a hijo. el feto, causando SG, una infección de alta prevalencia a nivel mundial, encontrándose en cuatro etapas: primaria, secundaria, latente y terciaria. Se pudo observar los impactos que ocasiona la sífilis durante el embarazo, su alta prevalencia en mujeres jóvenes, con baja escolaridad y baja clase social; cómo prevenir esta infección y cómo tratarla; forma de transmisión; Riesgos y lesiones causadas por mujeres embarazadas. Consideraciones finales: La necesidad de atención prenatal de calidad, tratamiento eficaz contra la sífilis durante el embarazo, evitando sus problemas, a fin de evitar el aborto, el parto prematuro, la sífilis vertical y la sífilis congénita. La sífilis tiene un impacto negativo en la vida de las personas. En este estudio se encontró que la producción científica en relación al tema es muy amplia y que la realización de exámenes y seguimiento a las gestantes durante el cuidado prenatal es fundamental.

Palabras clave: Embarazo, Sífilis, Treponema pallidum.

\section{INTRODUÇÃO}

Sífilis é uma infecção sexualmente transmissível (IST) causada pelo Treponema pallidum, pode ser prevenida ou tratada precocemente. Sua forma de contaminação pode ser sexual, vertical, sanguínea, adquirida ou congênita (LAFETA KRG, et al., 2016). Considerada um problema de saúde pública, a realização de exames e consultas durante o pré-natal se faz necessário para diagnóstico através do resultado reagente para VDRL, podendo realizar o teste treponêmico (FTA-ABS) para confirmação do resultado (PANDOVANI C, et al., 2016).

Por sua alta incidência, a sífilis adquirida antes da gravidez ou em qualquer fase da gestação é denominada sífilis gestacional (SG). Ligada a manifestações graves, pode causar: aborto espontâneo, parto prematuro, morte neonatal e/ou morte da gestante devido a suas complicações, suas fases variam de acordo com o estágio da doença (SUTO CSS, et al., 2016).

Podendo ser classificados como: primária, secundária, latente e terciária. A sífilis primária tem como sintoma característico o cancro duro; a secundária se dá quando a fase primária não é tratada e aparecem manchas no corpo e palmas das mãos, demonstrando que a bactéria se espalhou pelo sistema linfático e sanguíneo. Quando esses sintomas desaparecem caracteriza-se a fase latente da doença. A fase terciária inclui os sintomas da secundária e pode lesionar o sistema nervoso e cardiovascular, levando a morte (RAMOS MG e BONI SM, 2018).

$\mathrm{Na}$ sífilis congênita, que ocorre pela falta de tratamento ou interrupção, a bactéria atravessa a via transplacentária contaminando o feto. $\mathrm{O}$ exame VDRL é realizado no primeiro trimestre e repetido no terceiro com a finalidade de identificar tal agravo. Em caso de resultado positivo é iniciado o tratamento da gestante e de seu parceiro com a medicação que será administrada de acordo com a fase da doença, realizado em tempo hábil obtém bons resultados. A penicilina $G$ benzatina é a medicação indicada para este tratamento, porém deve ser finalizado o uso da mesma 30 dias antes do parto (TREVISAN MG, et al., 2018).

Diante do exposto surge o problema de pesquisa: Quais as evidências científicas encontradas na literatura acerca dos impactos da sífilis durante a gestação? Mediante isso, foi definido como objetivo geral: Identificar as evidências cientificas acerca dos impactos da sífilis durante a gestação. A presente pesquisa se justifica com a observação do aumento considerável de números de casos de sífilis no País. Diante do exposto teve o intuito de evidenciar impactos da sífilis em gestantes e consequentemente uma fonte de orientação a essas mulheres sobre a importância do tratamento dessa Infecção Sexualmente transmissível (IST). 


\section{REVISÃO BIBLIOGRÁFICA}

\section{História da Sífilis}

Sífilis é uma doença infecciosa sistêmica provocada pela espiroqueta treponema pallidum, com evolução crônica e assintomática, tendo como forma de transmissão a via sexual e vertical. Pode ser encontrada de duas formas, adquirida e congênita. A congênita é de notificação compulsória, tendo que ser registrado todos os casos. A sífilis adquirida se divide em precoce e tardia, conforme o tempo que a infecção está instalada no organismo e do grau de infectividade, a congênita, tem forma variável, acontecendo de forma assintomática, ou formas mais graves, no qual pode ser curada facilmente e encontrada apenas no ser humano (LÁFETA KRG, et al., 2016).

De acordo com Kalinin Y, et al. (2016) a sífilis teve seu agente etiológico descoberto em 1905, por Schaudinn e Hoffmann, seu primeiro nome foi Spirochoeta pallida por ser de cor "pálida" ao ser observado através de microscópio, porém no mesmo ano teve seu nome mudado para o qual, até os dias atuais é conhecida, Treponema pallidum. Em 1906 Wassermarn descobriu suas reações sorológicas e teve uma grande importância para o conhecimento dessa infecção.

Segundo a OMS (2019) a sífilis e uma infecção conhecida mundialmente, sendo com 6 milhões de casos novos durante todos os anos. A mulher grávida infectada deve receber o tratamento adequado, caso isso não aconteça pode ocorrer a transmissão vertical da mãe para o feto, essa infecção provoca nascimento prematuro, baixo peso ao nascer, aborto, natimorto, sendo a segunda causa de morte fetal que pode ser evitada no mundo.

É uma infecção sexualmente transmissível (IST) que vem prevalecendo mesmo com todas as tentativas para sua eliminação. Mesmo com eficácia da penicilina benzatina no tratamento, o paciente pode chegar a cura; acometida pela sífilis quando não tratada adequadamente a gestante evolui com complicações, o recémnascido, é acometido com a sífilis congênita (CARDOSO ARP, et al., 2018).

Da mulher para o feto se dá a transmissão vertical, concepto está contaminado por ter entrado em contato com a bactéria, corre vários riscos durante a gestação. Podendo ocasionar aborto, óbitos neonatais, perdas fetais tardias, neonato doentes ou assintomáticos que evolui com complicações se não forem tratadas (DOMINGUES RMSM, et al., 2014). A bactéria Treponema pallidum é uma espiroqueta responsável pela sífilis. Infecta o ser humano, é transmitida durante a gestação da mãe para o feto, quando não diagnosticada de maneira precoce, pode ser transmitida por transfusão sanguínea e principalmente por contágio sexual, sendo então uma infecção sexualmente transmissível (IST). Organização Mundial de Saúde estimou em 10,6 milhões de casos novos de sífilis mundialmente (PINTO M, et al., 2016).

Grávidas com menos de 20 anos apresentam maiores riscos em contrair a sífilis durante a gestação, devido à instabilidade que é comum nessa idade, a exposição ás infecções sexualmente transmissíveis, ocorrem em decorrência da relação sem proteção em que as mesmas expõem-se, por influências dos amigos, momento em que estão se descobrindo e não tem a devida preocupação com estas infecções, mesmo tendo conhecimento da existência e os riscos ocasionados por cada uma, deixam de usar preservativos e tem mais de um parceiro sexual. O nível social, o tempo livre que essas adolescentes têm, assim como o grau de escolaridade, também mostra o índice elevado existente de sífilis gestacional (PANDOVANI C, et al., 2018).

\section{Formas de Contágio}

De forma geral, as IST's são doenças infecciosas e o principal meio de transmissão se dá por via sexual, pode ser também transmitida verticalmente (de mãe para o feto), por via indireta agulhas e seringas compartilhadas, tatuagens transfusões sanguíneas aumentam a probabilidade de infecção dessas pessoas com a bactéria do Treponema pallidum que causa a sífilis (SUTO CSS, et al., 2016). O contágio da sífilis se dá através do seu agente etiológico Treponema pallidum espiroqueta que é adquirida durante o ato sexual desprotegido ou pela transmissão vertical, também pela disseminação hematogênica da bactéria através da circulação sanguínea da mãe em que atravessa a placenta causando assim a infecção do feto, no qual pode acontecer em qualquer fase da gestação. Podendo também ser transmitida através do aleitamento materno, caso a mãe do recém-nascido tenha lesões mamárias serão infectadas (RAMOS MG e BONI SM, 2018). 
Sendo uma infecção, em que o contato com a bactéria se dá inicialmente pelo ato sexual, o uso de preservativos masculino e feminino, ou o mínimo de troca de parceiros, já seria uma forma de evitar a contaminação por essa bactéria, na transmissão vertical por via transplacentária ou por sangue (COSTA LD, et al., 2018).

A transmissão dessa infecção acontece de várias formas, pela relação sexual sem uso de preservativos, através da gestante contaminada pela bactéria T. pallidum contamina o seu concepto, essas são as formas mais comuns de contágio com esse agravo. Através de alguns estudos realizados evidenciam que a transmissão pode acontecer também pelo beijo, de pessoas infectadas pela bactéria, quando existe lesão secundária na boca, acontecendo também quando as normas de biossegurança, não são adotadas adequadamente profissionais de saúde podem se contaminar com a bactéria que causa a sífilis caso tenham contato com sangue contaminado (KALININ Y, et al., 2016).

\section{Sífilis na gestação}

Introduzida como uma infecção sexualmente transmissível, os registros de notificação compulsória por conta da incidência, a sífilis na gestação vem variando de 30\% a 100\% de infectados, por não ser tratada adequadamente, as gestantes que tenham indicativo desta infecção serão acompanhadas durante as consultas de pré-natal para realização do tratamento e controle desta bactéria. Importante também enfatizar que não somente essa gestante deve ser tratada, mas também seu parceiro sexual, evitando assim a reinfecção, mesmo os homens ainda tendo uma forte resistência em irem ao hospital é preciso mostrar essa necessidade de aderir ao tratamento (OLIVEIRA DR e FIGUEIREDO MSN, 2011).

A Sífilis congênita bem como na sífilis durante a gestação são ligados alguns fatores que causam ameaças a saúde dessas mulheres, assim como baixo nível social, não ter um parceiro fixo, não usar preservativo durante as relações sexuais, ser dependente químico, nível de escolaridade baixo. Podendo causar aborto espontâneo, parto prematuro, consequências permanentes no recém-nascido, levando a morte neonatal (OLIVEIRA DR e FIGUEIREDO MSN, 2011).

A elevada incidência nos casos de sífilis em gestantes, está relacionada com alguns fatores importantes, todos os casos de sífilis durante a gestação devem ser registrados e notificados durante as consultas de prénatal e quando essas notificações não são realizadas da forma correta o seu tratamento é inadequado, aumentando assim o número de casos de sífilis em gestantes e sífilis congênita no Brasil. Nas consultas perante essa infecção durante o pré-natal o auxílio dos profissionais de saúde é de suma importância, uma vez que causam resultados negativos nas grávidas e nos recém-nascido. Qualquer tipo de dúvida do casal deve ser, sanada em relação a essa infecção e a mesma deve realizar os exames novamente depois do tratamento, verificando se foi eficaz o resultado durante a utilização do recurso terapêutico e o tempo que essa gestante foi tratada (SUTO CSS, et al., 2016).

De acordo com o DATASUS esse agravo vem aumentando ao passar dos anos, o acompanhamento durante o pré-natal deve ser iniciado o mais precoce possível assim que a gravidez for confirmada, o mínimo de seis consultas durante esse período e a realização dos exames, serem repetidos a cada trimestre são estabelecidos pelo Ministério da Saúde, tentando assim obter a redução de números de casos de sífilis congênita e também as consequências causadas por esta infecção (BRASIL, 2017).

\section{Sífilis Congênita}

Sífilis congênita acontece quando a gestante é infectada pelo Treponema pallidum e não faz o tratamento adequado ou é tratado, porém seu parceiro não é tratado como deveria ser. Desta forma pode acontecer a reinfecção dessa gestante. A sífilis congênita é uma infecção previsível, de tratamento fácil, eficaz e barato. A gestante não tratada transmite a infecção causada pela bactéria que atravessa a barreira transplacentária causando (SC) ou vertical, assim o concepto é infectado pelo Treponema pallidum vários agravos são ocasionados. A realização e o tratamento correto e das consultas de pré-natal evitam a incidência de sífilis congênita (NONATO SN, et al., 2015). Está infecção é inserida em um quadro no qual mostra que a sífilis congênita, pode ser evitada, com a realização dos exames e os mesmos sendo reagente é indicado o início do tratamento com a penicilina benzatina o mais precoce possível, a não realização do tratamento causa 
infecção do feto (transmissão vertical), causando vários eventos adversos na gestação, morte fetal, aborto espontâneo, natimorto, parto prematuro, sífilis congênita, deficiência mental sendo encontrada tardia ou recente. A recente é diagnosticada até os dois anos de vida da criança e a tardia depois de dois anos de vida, o teste é realizado durante as consultas de pré-natal e ao ser tratada adequadamente a gestante que foi diagnosticada com sífilis não transmite a infecção para o feto (BRASIL, 2015).

Ainda causa consequências graves nos recém-nascidos, esta doença encontra vários impedimentos, seja financeiro, regional, comportamental, continua sendo um desafio para todo o Brasil, a luta contra sífilis congênita, o diagnóstico dessa infecção nesse recém-nato ainda é complicada devido o mesmo ter nascido assintomático, tanto por conta dos anticorpos da mãe como pela dificuldade de cultivar o treponema pallidum, a história materna é de extrema importância para estes recém-nascidos, pois com o resultado positivo da mãe para diminuir o risco de contaminação para o concepto esta infecção e o tratamento dá mesma, já que é uma infecção que atravessa a barreira transplacentária (HEBMULLER MG, et al., 2015).

Mundialmente o número de gestantes infectadas pela sífilis vem crescendo ao passar dos anos durante a gestação essas mulheres não fazem os exames que detectam a sífilis ou fazem esses testes que dão o resultado positivo, porém não seguem o tratamento adequado, resultando assim a infecção vertical ao ser transmitida a sífilis para este concepto ocasiona a sífilis congênita em que causa morte fetal, parto prematuro, baixo peso, morte neonatal, cegueira, surdez, deficiência mental (NONATO SM, et al., 2015).

A gestante com sífilis, que não realiza o tratamento adequado transmite a bactéria para o feto, os neonatos com chances de adquirir sífilis congênita são submetidos a vários exames para se diagnosticar essa infecção podendo ser feito punção lombar, exames radiológicos e em alguns casos, ficar internados durante 10 dias no mínimo para realização de tratamento. Uma gestante infectada com a bactéria e ainda não detectada corre o risco de contaminar esse feto, pois com a realização do tratamento correto e registrado durante o pré-natal evidenciam chances dos recém-nascidos não serem contaminados (HEBMULLER MG, et al., 2015).

No Piauí de acordo com (DATASUS) nos anos de 2017 e 2018 o número de casos confirmados de sífilis em gestantes aumentou significativamente, 2017 foram registrados 477 casos novos e no ano de 2018,612 casos confirmados. Esses dados mostram que houve um aumento de 135 casos registrados a mais de um ano para o outro no Piauí. Em nível de Brasil o número de casos foi de 53.839 em 2017 e em 2018 passou para 59.022 casos notificados (BRASIL, 2017).

\section{Pré-Natal}

Na gestação é realizado às consultas de pré-natal que são de extrema importância e o início do pré-natal tardio pode causar sérios problemas durante a gestação e mesmo depois dela, assim para reduzir o número de mortes o indicado é iniciar o pré-natal o mais cedo possível e evitar agravos ocasionados por conta da sífilis, a sífilis congênita é uma infecção de notificação compulsória desde 1986, e no ano de 1993 devido ao alto número de casos de sífilis foi sugerido aos países latino-americanos a erradicação da infecção da sífilis sendo está um problema de saúde pública (OLIVEIRA DR e FIGUEIREDO MSN, 2011).

A partir de 2005 a sífilis em gestante começou a ser notificada no qual estas notificações são registradas durante as consultas de pré-natal com os resultados de sífilis reagente positivo, para essas gestantes, esse acompanhamento na maior parte é feito pelo enfermeiro e o mesmo realiza a primeira consulta e que vai verificar a classificação se é de baixo ou alto risco essa gestação e se for de baixo risco o acompanhamento se dá com o enfermeiro que acompanha toda a gravidez, fica atento a detectar precocemente está infecção, assim como conversar com essa gestante com diagnóstico positivo sobre a necessidade do tratamento e que a mesma não precisa ter vergonha de ter contraído uma IST e sim de cuidar e evitar suas consequências e ter todos os cuidados necessários (OLIVEIRA DR e FIGUEIREDO MSN, 2011).

Depois que a gravidez é confirmada, começam as consultas de pré-natal no qual a gestante será cadastrada no SISPRÉNATAL e todos os dados são anotados tanto na ficha como no cartão de gestante, irão começar a receber orientações que se fazem importantes em relação ao acompanhamento do pré-natal, consultas e visitas domiciliares, solicitações dos exames necessários, atualização do calendário vacinal. Essas consultas são realizadas na Unidade Básica de Saúde (UBS) seis consultas são preconizadas no 
mínimo, tendo consultas alternadas com o médico e enfermeiro. As consultas de pré-natal devem ser iniciadas o mais rápido, assim também a realização dos exames que irão indicar o estado de saúde da gestante e podendo evidenciar infecções (BRASIL, 2013).

\section{Rede Cegonha}

A Rede Cegonha foi criada pelo ministério da Saúde (MS) em 2011, na área do Sistema Único de Saúde (SUS). Essa estratégia é fundamentada em quatro partes pré-natal, parto e Nascimento, puerpério e atenção integral a saúde da criança, sistema logístico. A realização da atenção ao parto e ao nascimento está fundamentada na confirmação da melhoria, na assistência em estratégias eficazes para os atendimentos maternos e neonatais, visando garantir que a mulher tem direito em planejar sua vida reprodutiva e ter uma atenção humanizada durante a gravidez, ao parto e puerpério. Assim como os recém-nascidos têm direito ao nascer seguro ter um bom desenvolvimento saudável. No qual o ministério da saúde tem como objetivo com programa Rede cegonha, a atenção dessas mães e recém-nato (LOPES GC, et al., 2019).

A realização dos testes rápidos e triagem de sífilis durante a gravidez é feito junto com atenção básica e a rede cegonha assim como o SUS, que viabilizam estratégias com o Ministério da Saúde, que buscam capacidade e o aumento da sociedade brasileira em busca da análise da sífilis nessas pessoas. Assim essas estratégias ofertam, testes rápidos de sífilis ampliam os locais de realização dos testes e exames complementares assim como tratamento para a sífilis além de registrar todas essas informações nos seus devidos sistemas (BRASIL, 2017).

De acordo com Ramos MG e Boni SM (2018), a Rede Cegonha (RC) presta cuidados e tenta convencer a importância dos testes rápidos na detecção de algumas IST's, cuidados intervenções necessários para evitar a contaminação com estas infecções, além dos profissionais receberam práticas de como trabalhar e realizar esses testes. Essas mulheres recebem uma atenção para assim garantir a capacidade e elaboração de um plano de como se prevenir e ter seus filhos quando decidirem, o momento certo e os cuidados durante a gestação, reduzindo assim os óbitos e consequências de um acompanhamento, que não seja eficaz, visando a melhoria do atendimento na atenção primária. Os testes foram implantados nessa estratégia evitando a contaminação dos conceptos e seus agravos.

\section{Tratamento para Sífilis}

O tratamento da gestante com sífilis tem grande importância para saúde pública, no qual são primordiais, mantendo controle e prevenção da sífilis congênita. Os exames realizados durante a gestação são solicitados pelos profissionais de Saúde da Estratégia de Saúde da Família (ESF), como também o tratamento de acordo com o resultado dos exames, o tratamento pode ser iniciado mais breve possível. A subnotificação acontece por conta da má assistência realizada durante o pré-natal e a falta do tratamento adequado, a notificação dessa infecção permite ter o controle, realizando as qual é determinada a dosagem a ser administrada na gestante, que tendo o resultado positivo para esta infecção, sendo assim o tratamento deve ser feito 30 dias antes do nascimento desse neonato evitando a sua contaminação com a bactéria, sendo de suma importância o tratamento do parceiro durante esse período, com todos esses cuidados a sífilis congênita não será desenvolvida por este feto (ZOILO CS, et al., 2018).

\section{CONSIDERAÇÕES FINAIS}

Constatou-se no presente estudo a necessidade da realização de pré-natal qualidade, de um tratamento eficaz contra a sífilis, durante a gestação evitando seus agravos, tendo como consequências aborto, parto prematuro, sífilis vertical e sífilis congênita. Constatou-se também que a sífilis tem impacto negativo na vida das pessoas, ainda existe muitos preconceitos em relação a essa patologia. A produção científica em relação ao tema é muito grande. É indispensável a realização de exames e acompanhamento das gestantes durante o pré-natal. 


\section{REFERÊNCIAS}

1. AGUIAR LC, et al. Sífilis materna: Análise de evidências referentes à falha no tratamento de gestantes. REV. Enfermagem Atual In Derme, 2019; 87(25).

2. ARAUJO MAL, et al. Fatores associados aos desfechos desfavoráveis provocados pela Sífilis na gestação. Rev. Bras. Saude Mater. Infant, 2019; 19(2): 411-419.

3. BRASIL. Ministério da saúde, Conitec. Penicilina benzatina para prevenção da sífilis congênita durante a gravidez. 2015.

4. BRASIL. Ministério da saúde. Organização Mundial de Saúde Publicadas Novas estimativas sobre sífilis congênita. Organização Pan-Americana (OPAS), 2017.

5. BRASIL. Ministério da Saúde. Secretária de Atenção à Saúde. Departamento de Atenção Básica. Atenção ao Prénatal de Baixo Risco [recurso eletrônico]. Ed.rev-brasília: Editora do ministério da saúde (Cadernos de Atenção Básica), 2013; 32: 318 p.

6. CARDOSO ARP, et al. Análise dos casos de sífilis gestacional nos anos de 2008 a 2010 em Fortaleza, Ceará, Brasil, 2018; 23(2):563-574.

7. COSTA LD, et al. Conhecimento dos profissionais que realizam pré-natal na atenção básica sobre o manejo da sífilis, 2018; 17(1).

8. DOMINGUES RMSM, et al. Prevalência de sífilis na gestação e testagem pré-natal: Estudo nascer no Brasil, 2014; 48(5).

9. DOMINGUES RMSM, LEAL MC. Incidência de sífilis congênita e fatores associados à transmissão vertical da sífilis: dados do estudo nascer no Brasil, 2016; 32(6).

10. FIGUEIREDO DCMM, et al. Relação entre oferta de diagnóstico e tratamento da sífilis na atenção básica sobre a incidência de sífilis gestacional e congenital, 2020; 36 (3).

11. GUANABARA MAO, et al. Acesso de gestantes às tecnologias para prevenção e controle da sífilis congênita em Fortaleza-Ceará, Brasil, 2017; 19(1):73-79.

12. GUIMARÃES TA, et al. Sífilis em gestantes e sífilis congênita no Maranhão, 2018; 25(2): 24-30.

13. HEBMULLER MG, et al. Gestações subsequentes em mulheres que tiveram sífilis na gestação, $2015 ; 20$ (9): 2867 2878.

14. KALININ Y, et al. Sífilis: Aspectos clínicos, transmissão, manifestações orais, diagnóstico e tratamento, 2016; 23(45): 65-76.

15. LAFETÁ KRG, et al. Sífilis materna e congênita, subnotificação e difícil controle, 2016; 19(1): 63-74.

16. LOPES GC, et al. Atenção ao parto e nascimento em hospital universitário: Comparação de práticas desenvolvidas após Rede Cegonha, 2019; 27.

17. MACHADO I, et al. Diagnóstico e tratamento de sífilis durante a gestação: Desafio para enfermeiras, 2018; 11(2): 249-255.

18. MARASCHIN MS, et al. Sífilis materna e sífilis congênita notificadas em um hospital de ensino, $2019 ; 22$.

19. NONATO SN, et al. Sífilis na gestação e fatores associados à sífilis congênita em Belo Horizonte-MG, 2010-2013, $2015 ; 24(4): 681-684$.

20. NUNES JT, et al. Sífilis na gestação: Perspectivas e condutas do enfermeiro, 2017; 11(12).

21. OLIVEIRA DR, FIGUEIREDO MSN. Abordagem conceitual sobre a sífilis na gestação e o tratamento de parceiros sexuais, $2011 ; 2(2): 108-111$.

22. PANDOVANI C, et al. Sífilis na gestação: associação das características maternas e perinatais, $2018 ; 26$.

23. PINTO M, et al. Carga treponêmica em amostras biológicas correspondentes a diferentes fases clínicas da sífilis, 2016; 5: 15-18.

24. RAMOS MG, BONI SM. Prevalência da sífilis gestacional e congênita na população do município de Maringá-PR, 2018; 11(3): 517-526.

25. SACARENI V, et al. Vigilância epidemiológica da transmissão vertical da sífilis: dados de seis unidades federativas no Brasil, 2017; 41.

26. SANTOS RRG, et al. Percepção dos profissionais para implantação do teste rápido para HIV e Sífilis na Rede Cegonha, 2018; 10(3): 17-29.

27. SUTO CSS, et al. Assistência pré-natal a gestante com diagnóstico de sífilis, 2016; 5(2): 18-32.

28. TREVISAN MG, et al. Prevalência da sífilis gestacional e congênita no município de Francisco Beltrão, 2018; 19(2).

29. ZOILO CS, et al. Fatores maternos associados à transmissão vertical da sífilis congênita, 2018; 12: 211-217. 